\title{
Strategies for Personal, Organizational and Professional Leadership Success
}

\author{
Bahaudin G Mujtaba ${ }^{1 *}$, Frank J Cavico ${ }^{1}$ and Tipakorn Senathip ${ }^{2}$ \\ ${ }^{1}$ Nova Southeastern University, USA \\ ${ }^{2}$ Ramkhamhaeng University, Bangkok, Thailand
}

*Corresponding author: Bahaudin G. Mujtaba, Professor of Management / HRM, Huizenga College of Business and Entrepreneurship, Nova Southeastern University, Fort Lauderdal, USA.

Received Date: January 04, 2020

Published Date: January 22, 2020

\begin{abstract}
Human beings have reflected on becoming and serving as successful leaders for thousands of years. Most people agree that leadership skills are composed of both art and science. Leaders who are performance-focused and developmental in their leadership styles characteristically are concerned with the well-being and success of their employees. Effective leaders attempt to develop their people through effective communication, motivation, vision, and interpersonal skills. Furthermore, these leaders develop and empower effective teams in their departments and organizations.

Based on a review of literature and the combined 100 years of experience among the authors, this article's philosophical, scholarly, and practical aspects build on one another, proceeding from general to specific, to provide some essential imperatives for successful leadership. More specifically, we look at the characterization of leadership and success from a common-sense point of view. We try to answer the question: can a person be an effective leader and be truly perceived as "successful" in society? We provide reflections on this topic along with relevant practical recommendations; and readers are encouraged to act in an efficient, efficacious, profitable, and honorable manner; and not just for this coming New Year, but to live and act this appropriate way for the rest of one's life. Finally, the article offers specific suggestions, and strategies for successful, ethical and sustainable leadership.
\end{abstract}

Keywords: Success; Leadership; Art; Science; Social intelligence; Professionalism; Situational awareness

\section{Introduction}

Leadership and success are not mutually exclusive; as such, both can happen simultaneously. Accordingly, it should be noted that not all good leaders are necessarily seen as "successful" in terms of finances or material wealth; and not all financially wellinformed successful individuals are viewed as good leaders. Success and leadership are defined by different traits. We believe that "success" can and should be defined by each person based on his or her desires, abilities, competencies, goals, and efforts. Consequently, it is not the place of organizational leaders to determine how successful a person can or should be based on his/ her first impression of the employee or on the associate's physical/ personality characteristics. Ralph Waldo Emerson said Mujtaba [1].

What is success? To laugh often and much; to win the respect of intelligent people and the affection of children; to earn the appreciation of honest critics and endure the betrayal of false friends; to appreciate beauty; to find the best in others; to leave the world a bit better, whether by a healthy child, a garden patch, or a redeemed social condition; to know even one life has breathed easier because you have lived.

Success can be "practicing what you preach," progressively realizing predetermined goals/ideals, and doing one's best to make worthwhile contributions to society Mujtaba [2,3]. Therefore, it is a moral imperative and obligation for managers and organizational leaders to proceed as though limits to employees' abilities do not exist; thus, each employee should be given fair opportunities to perform as per his or her desires, abilities, competencies, and dreams. Next, in this paper, we review several pertinent topics from the literature to glean relevant recommendations for personal success and leadership in the modern workplace, which can be applied by each professional as per his / her goals.

\section{Literature Review}

Two thousand years ago, Aristotle explained his "modes for persuasion," or rhetorical appeals, through the application of ethos, pathos, and logos to make others believe or see a certain point of 
view. As can be seen in Figure 1, the consistent application of ethos, pathos and logos can be the essential imperatives of leadership success since successful leaders must be ethical and credible, control their emotions and feelings, and use logic and reason to persuade others in the organization. Figure 1 - Imperative of Leadership Success

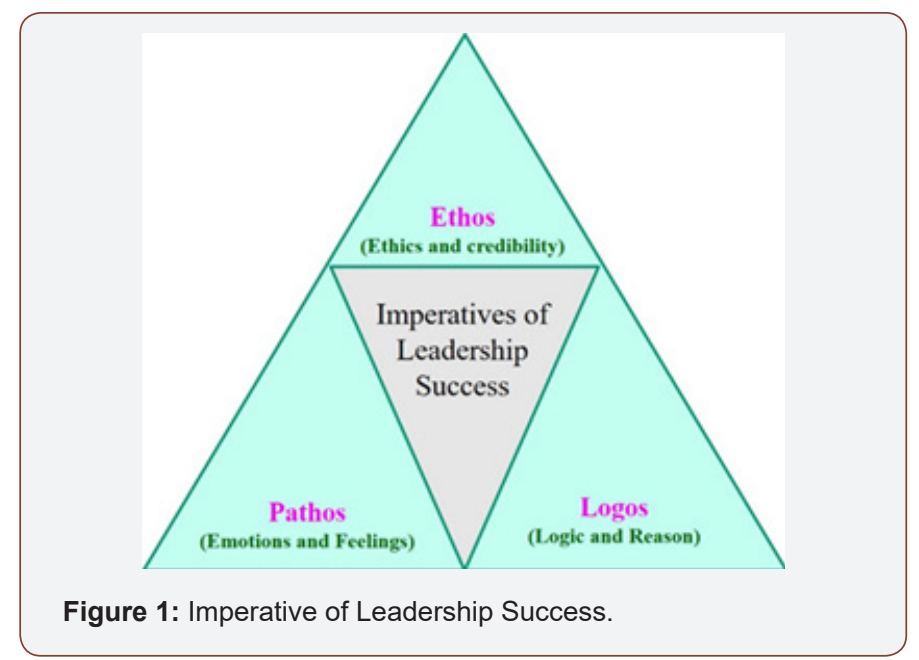

The aforementioned values are reflected in the book, entitled "Social Intelligence: The New Science of Success," written by Karl Albrecht [4]. Albrecht discusses some basic tenets of human relations that should be practiced by each leader and manager in the workplace. Albrecht's goal is to help professionals, managers and leaders see the beauty in human behaviors, and at the same time to let people understand those behaviors that differentiate effective leaders from ineffective ones. Effective leaders, according to Albrecht (2006), are those leaders who exhibit nurturing behaviors: behaviors that make people feel valued, capable, loved, respected, and appreciated.

Nevertheless, some people feel that leadership and success are only about financial wealth. When we read newspaper headlines, it is easy to find stories on how business executives, and in some instances employees, have become agents of unethical behavior motivated by immense greed and manifested in organizational theft. More recently, stakeholders have even sought to tightly link executive compensation to organizational performance. Albrecht (2006) notes that the basis for social intelligence is built on the principle of S.P.A.C.E. (situational awareness, presence, authenticity, clarity, and empathy). The situational awareness dimension highly relates to the concept of situational leadership, which, among many factors, takes into consideration the psychological and task readiness of the follower in terms of his or her development and responsibility delegation (Mujtaba, 2010, pp. 200-202).

The "S" factor represents situational awareness or the individual's situational radar and ability to understand and empathize with people in different situations. Situational awareness, which is similar to situational leadership skills, can be tied to a leader's ability to sense people's readiness to successfully complete as task as well as their feelings and intentions. How well can a leader study the environment, the culture, the social rules, and norms, and use these differences to appreciate the various points of view without being judgmental? Good situational radar demonstrates the leader's concern for people, his or her deep respect for others, and his or her ways of thinking. Situational awareness includes the leader's belief in multiple ways to solve problems as well as the leader's belief that he or she is not selfcentered. A self-centered individual will find cooperation by others difficult to accept; consequently, he or she will find it difficult to get people to accept him/her or share themselves with him/her.

"P" stands for presence, or the way the leader affects others through his or her physical appearance, mood and demeanor, body language, and approachability. Albrecht states that leaders' behaviors mustcommunicate a sense of confidence, professionalism, kindness, and friendliness to the followers. The leader's presence in the mind of his or her followers must not be viewed as depressing, indifferent, or insecure. As a leader, one must pay special attention to the sense of presence he or she is communicating to others in order to be accepted and taken seriously.

"A" stands for authenticity, which measures how honest and sincere a leader is, both to him or herself and to the followers. According to Albrecht, "authenticity is about the desire and ability to let yourself be real, not phony or contrived. It's how you connect with other people, so you become worthy of their trust." Leaders must be viewed as straight-up, someone who believes in doing the right thing, and stands up for what he or she believes in. Authenticity means a solid, trustworthy person with a positive attitude and an upstanding character.

The "C" in S.P.A.C.E. means clarity. Clarity is the leader's ability to make him or herself known and clearly so to his or her followers. Clarity measures one's ability to express your thoughts, opinions, ideas, and intentions clearly to one's audience or listeners. Albrecht argues that organizational leaders must examine their communication skills and ask: do you say what you mean and mean what you say? Do you speak too fast, too much, or not at all? Does your voice pitch, rate, volume, and inflection inspire confidence or disrespect? Do you use language skillfully? Can you frame concepts and issues for others in an articulate, compelling way? Do you listen attentively and skillfully? These questions should be tied to the organization's behavioral model; and, accordingly, should be expected of every leader in the organization. Awareness of one's mode of communication makes communication better and puts more clarity into one's intention or purpose. Albrecht states that, "Certain patterns of language, either aggressive, dogmatic, or restrictive in their implications, can alienate others, contaminating the process of understanding." To influence other people with our ideas and thoughts, leaders must present the information in a way that makes it easy and fast for people to understand.

Finally, "E" stands for empathy, which addresses how considerate the leader is to people's feelings. The leader must be able to show people that he or she can identify with and appreciate them for 
who they are. It is this sense of connectedness that establishes a condition of rapport between two people and inspires followers to cooperate with their leaders. The author provides two ways for leaders to ensure that they are perceived as caring. Albrecht urges leaders to avoid or abandon toxic behaviors and increase the use of nourishing behaviors. Empathy, according to the author, is a longterm investment and not an episodic application of charm. Albrecht believes that leaders cannot expect followers to respect and accept their leadership if they constantly abuse, insult, and make them feel insignificant or unworthy. The road to complete acceptance is to get people to share a feeling of connectedness with you as a leader, thereby making them closer, rather than farther from you.

Sadly, is a fact that inappropriate behaviors by leaders and employees make employee engagement difficult, and it makes effective relationships a difficult objective to achieve in the organization. However, effective interpersonal relationships are an important tool for quality leadership and both organizational and personal success. As such, in this article, we offer some success strategies that can be applied by all individuals so they can be considered successful leaders Figure 2.

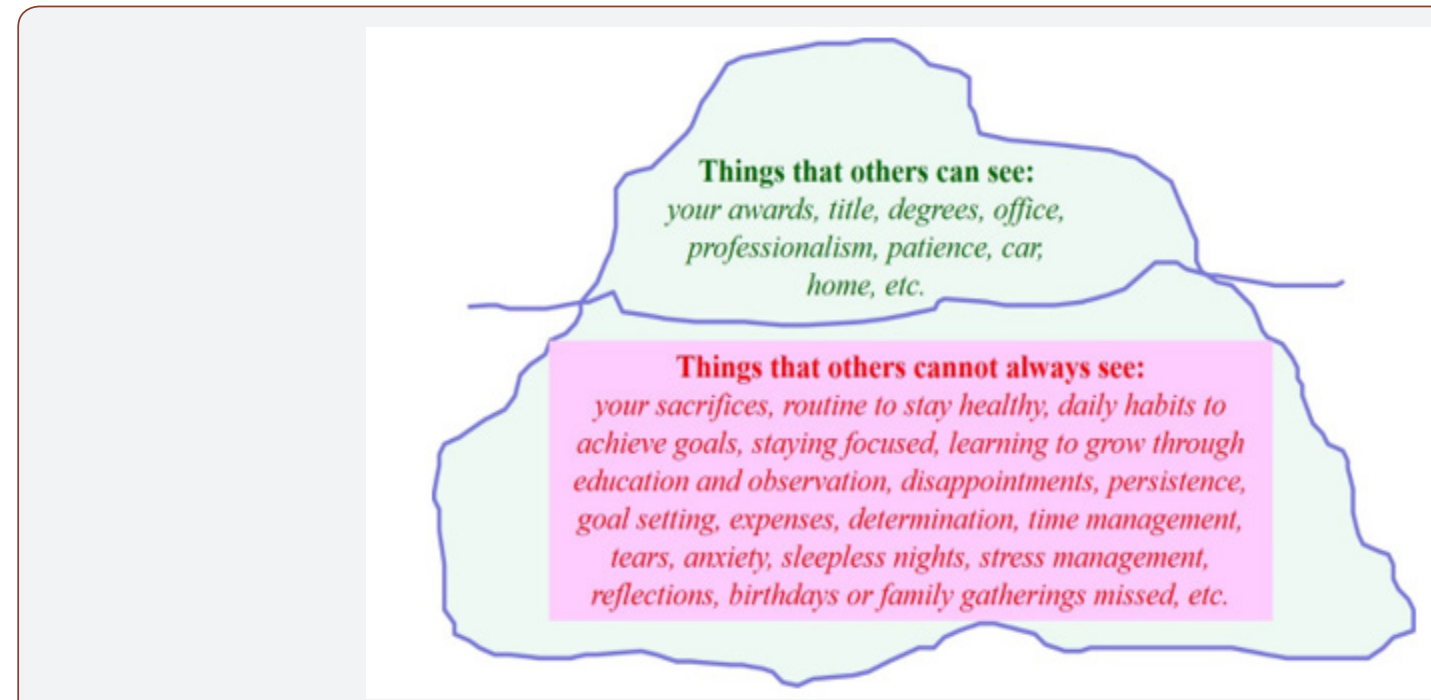

Figure 2: The Iceberg of Success.

The strategies mentioned in this article are not only philosophies based on the work of thousands of authors and experts in the field; but also most of them have been personally applied by us as authors both in our personal and professional lives over the past half-century. As exhibited in Figure 2, success can be like an iceberg where the results can be observed, but the process of getting there is not always apparent to the naked eye. For example, the results of success can be receiving awards, titles, degrees, having a corner office, professionalism, patience, having a nice car, or a big home that are apparent as symbols. However, things that others cannot always see regarding the process of becoming a success are often underneath the iceberg such as the sacrifices that one has to make, the routine of dieting and exercising to stay healthy, and one's daily habits to achieve pre-determined goals in a timely manner. It is the persistent and effective application of characteristics and habits that are below the waterline that eventually lead to the outcomes which are observable and above the waterline. In this paper, we highlight those traits and habits that fall below the waterline on the iceberg, which are not necessarily seen or observed by others, but they are the foundational imperatives of sustainable personal success.

Modern leaders, therefore, need to self-assess and reflect on the forthcoming habits and strategies for sustainable success along with their own definition of leadership and success as well as those of their associates in order to bring about positive changes, appropriate policies, and to lead the development of their employees in a timely manner. Concurrently, leaders and managers need to reduce the negative impact of their footprints such as undue stress, conflict, pollution, etc. in their departments, organizations and society at large Mujtaba [5,6]; Senathip, Mujtaba and Cavico [7]; Cavico and Mujtaba [8]; Ahmed et al. [9]; Ahn, Adamson and Dornbusch [10]; Sungkhawan, Mujtaba, Swaidan, and Kaweevisultrakul [11]; Allegretti [12]; Wolf \& Mujtaba [13]; Alon and McAllaster [14]. Consequently, on the following pages, while building on the previous literature and discussion, we are offering some findings and recommendations about success and leadership skills related to goal setting, education, soft-skills, personality, common sense, respect, self-interest, stress, professionalism, risktaking, and gaining "good luck."

\section{Findings and Recommendations}

\section{Goal setting and achieving}

We believe that success is the progressive realization of worthwhile and predetermined goals. As such, it is important that each person first clarifies his/her goals; then, assess that those goals are aligned with one's personal values; and, finally, make sure that the achievement of each goal is worthwhile for oneself, one's family, and the society overall in a sustainable manner. This way, you can keep going in the direction of your goals, even if moving or progressing slowly, eventually you will get to your destination.

Goal setting and achieving are both an art and a science. Start with the achievement of small and "doable" goals so you can 
master the skills necessary to achieve them. The authors stress that it is imperative that you set worthy and attainable goals. Aim prospectively high; think "big"; but start out presently in a modest manner. Thus, it will be useful to break down your goals into smaller and more manageable; and thereby to set forth more achievable objectives. Fit your short-term objectives into your long-term goals. Set your primary goals, which will require most of your effort; and then set your secondary goals, which will require less effort. Obviously, effort is critical to achieving goals; but so is prioritizing and being focused.

Be committed to attaining your goals; be passionate and optimistic; yet be patient, but persistent. Set deadlines in the form of timetables, for achieving goals and doing tasks. Moreover, limit the amount of time even for achieving important objectives; and try to adhere to those periods; but be realistic. Also, be prepared for unexpected interruptions and problems. Furthermore, see if you can accomplish more than one secondary goal together in one set time-period. You should be, and continue to be, systematic and methodical in documenting your successes in working towards and achieving each goal. Learn and document the strategies that work and avoid those that are not fruitful.

Moreover, it is very important to success for you to take a longterm perspective; that is, be willing to undergo some short-term sacrifice and expense in order to maximize your own greater longterm good. Execute your strategy for success; for example, have "to-do" lists (short-term and long-term); have goals and objectives that are attainable; achieve them; and then set more goals and objectives.

Differentiate between those actions and tasks, which appear urgent versus those that are important. Tasks and actions which are urgent and important should be done quickly; then focus on those tasks which are important; and, if the urgent tasks are not important then you can avoid them or simply delegate them to someone else. Prioritizing is an important ingredient to success. Accordingly, have a clear, definite, and achievable set of priorities; have strategic objectives as well as the tactics to achieve them. Realize that as the business or organization grows, you must focus on the key objectives that will lead to success. As noted, learn to delegate to others the achievement of the other objectives that are not critical for you to achieve as the leader of the entity. However, also be prepared to renegotiate prior commitments if you are overburdened with work.

The idea is to achieve a proper balance between the time and effort you need to lead and manage the business or organization and the time you need to work yourself on critical projects. You will likely be more productive if you do not micro-manage every aspect of the business; but rather mainly commit yourself to the performance and attainment of certain important goals. As such, the more time you have to study the "big" issues or problems, to fully understand them and to develop solutions, and to more carefully implement and supervise solutions. When new issues or problems emerge, be careful not to overload or overwhelm yourself with work; rather, be prepared to re-order your priorities and to delegate some work to others. Try to avoid unnecessary interruptions when working to achieve goals; consequently, do not give employees and other people the "liberty" to interrupt you continuously; learn to say, "No" and "do not bother me," but be polite and courteous in so doing.

Learn effective delegation. Be a "good" delegator; that is, do not merely "hand-off" projects to others, but choose your delegates carefully based on their knowledge, skill, training, motivation, as well as the ability to understand instructions and work independently or in teams, as required. Make sure they are committed to the project and that they have the resources they need to complete it. Moreover, make sure that you establish parameters for completion and; check their performance regularly while providing relevant feedback based on the assessment of whether standards have been met or not. Always remember that even though you delegated a project to a subordinate, you as a leader or upper-level manager are still responsible for its timely, full, and adequate execution.

\section{Education}

Education is critical to personal, business, and professional success, as well as to be a successful leader. Accordingly, one must develop the requisite skills, knowledge, and expertise to achieve success. One thus must undergo pertinent training, education, and continuing education, including workshops, seminars, and professional development. Moreover, you must be prepared to "re-tool" yourself if necessary. First, develop the "hard skills." Obviously, make sure you have the basic competencies in the "3Rs": reading, writing, and arithmetic. Then accelerate, expand, and improve your scope and rate of education and learning. Start parttime, temporary, and/or at the entry-level, if necessary, but start! As such, gradually acquire the knowledge, skills, and experience you will need to achieve proficiency; and then advance to more full-time education and learning. Also, learn by doing; and maybe learn the "hard way," that is, from trying new approaches through strategic experimentation, and consequently learning from the experience and mistakes. Moreover, admit mistakes; and then be willing to, and be able to, be self-educated and self-trained. The mark of a mature person is to "own" your errors, learn from them, and be able to move forward from your errors. Accordingly, take responsibility for your actions, which is what trustworthy people and true leaders do.

The objective is to achieve excellence and to become recognized as being very good at something as well as a high achiever. That is, make yourself regarded as a "go-to" person. Help others, even though you may be acting outside of the technical scope of your duties. Most importantly, help take work away from boss and thereby reduce the workload and stress of the boss; and thereby be regarded as a dependable and essential person by the boss. However, you also must be keenly aware of your "blind-spots," that is, areas that you are weak in and consequently need to develop. Yet, also be cognizant of your "hidden-strengths," that is, talents and skills that you are not using and/or publicizing that you possess. You must be aware today that there is a societal expectation that business will act not "merely" in a legal manner, but also ethically 
in a moral manner, as well as in a socially responsible as well as "sustainable," that is, environmentally responsible, manner. In addition, since today the economy is truly a global one you must be aware of globalization, and in particular, you must be aware of not only the laws of the U.S., but also the laws of the host countries you are doing business in, as well as the extraterritorial effect of U.S. laws. Education is the key, and "to be forewarned is to be forearmed"! [15].

\section{"Soft-Skills"}

In addition to the "hard-skills," it is also very important that you develop some of your relevant "soft-skills," that is, have a positive attitude, be optimistic, possess a good work ethic; have traits of honesty and integrity, and exhibit good communication skills, cultural competency, and sensitivity. Also important is having strong collaboration skills; that is be able to collaborate and arrange collaboration to effectuate strategies and achieve business or organizational goals. Create and develop collaborative relationships where both parties receive value. Accordingly, you must view employees as "human investments." Realize as employees grow and develop, so too will you and your organization, including its profitability. The objective is to create an environment where employees feel they can voice their opinions freely without fear of repercussions. As such, develop relationships at work - mentors/ coaches, confidantes, friends. Look for hidden and untapped potential in employees and others; and then seek to draw them out into jobs or tasks you feel they would be good at naturally. Yet be cognizant of the fact that it can be a "hard sell" to push people into jobs and tasks they feel they are not qualified for or able to do. Always be positive, passionate, and excited about work and goal attainment. As a result, you will attract like-minded people. Celebrate achievements and recognize accomplishments, which will create high morale, motivate employees, and thus help to achieve goals as well as increase productivity. Help employees achieve their goals - both inside and outside the company; ensure that employees have the tools they need to get the job done. Guide your employees, lead people through inspiration and transformation, give direction as relevant, manage when needed; but also empower associates and followers; and be prepared to serve as a role model.

Express gratitude, for example, simply saying "thank you" or writing a short gracious note, for work well done and/or for help and assistance provided. Gratitude, if genuine, will create and strengthen relationships, build-up employees' self-esteem, foster trust and loyalty, and increase motivation and productivity. Talk to employees, and encourage managers to do so too, about company values and the mission. You will see that the result will be to help people feel more connected to the company's mission and values; and thereby try to align company's vision and values with those of employees, for example, changing the world for the better by producing a particular product or providing a certain service.

Create opportunities for the employee's advancement and growth; offer education, training, support, and structure. Demonstrate that you are interested in the employees' advancement and success. Also, offer opportunities to move among positions for cross-functional development. Build relationships with employees and people; get counsel and "feedback" from them and others - family, co-workers, clients, and customers. Always entertain different points of view; and listen to different points of view with a sense of understanding. Encourage and allow people to "say what needs to be said," to challenge and question ideas and policies, as well as allow debate, but always in a respectful manner and a positive tone. Open-up issues and questions for discussion and sharing of opinions, regardless of a person's position or title. Listen to others at work; help others at work; empathize with them; and thus make them true colleagues and "allies." Also, help them "pickup the slack"; invite co-workers to lunch; organize office activities; the result will be more engaged employees, a very harmonious work environment, and more committed and productive employees.

\section{Pleasant personality}

There is "the power of being polite," as the old maxim says. That is, be a nice person and have a pleasant personality. Be open and transparent with people. Be forgiving and compassionate; be patient with other people's mistakes. Give praise when well deserved; and render criticism in a constructive and respectful manner. The result will be that you will be liked, and you will have friends, allies, and team-members. In addition, you will create a harmonious atmosphere which will give people, especially your employees, the "comfort level," drive, and motivation to do excellent work. Similarly, you must be modest and humble; and you must avoid arrogance. Be willing to praise people and their success; and be willing to share credit for successes too. Most importantly, avoid negativity and negative people; as such, associate with positive people. Do not be negative with yourself; do not admonish yourself; and do not reflect negativity. Rather be happy; and look for people who are happy and satisfied with life, and hire and promote them, as they usually will be very pleasant and productive associates.

\section{Common Sense}

Common sense is a very important ingredient to success. Accordingly, find out what you like to do and do well; yet note that you do not have to be good in everything. As such, realize that others will be willing and able to assist you in weak areas. Moreover, find out what you do not like to do and do not do well, as that is part of the self-education process. Obviously, "go with your strengths." Initially, do not worry if you are not sure what direction you should take; ultimately, you will figure it out, perhaps by "trial-and-error." Yet keep on trying; keep on striving; look for opportunities to take advantage of; and make your own opportunities by being persistent, watchful, and ready. Moreover, always remember the old maxim: "There is a person for every job and a job for every person."

\section{Role Models}

Look for role models in the form of virtuous and successful people. These role models can serve as formal and informal mentors and coaches. Learn from them and seek their advice and counsel. You will see that successful people develop successful habits, which 
they maintain and refine on a consistent basis. See what they are doing and do well and emulate their successful habits. Learn from mentors and coaches; keep them engaged or "in the loop", while seeking their advice and counsel often. Particularly, look for successful and ethical leaders who recognize and nurture talent, and who are willing to spend time with you, take an interest in you, and answer the questions that you ask. That is, essentially, look for role models and leaders who are willing to "take a chance on you."

\section{Respect}

To be truly successful and to sustain that success, you must create a culture of morality, respect, mutual support, caring, and openness; and you should strive to create a culture of happiness and fun too. Establish a culture built on a solid foundation of morality, respect, recognition, and well-earned and well-deserved rewards. Value and cherish diversity among people; and as such be cognizant of the fresh ideas, opinions, and perspectives that diverse people and cultures can bring forth. Always, always, treat people with respect and dignity; demonstrate that the company cares about its employees as individuals. Accordingly, do not treat people merely as a "number," "thing," tool or instrument. People are people, that is, human beings, and they must always be treated with dignity and respect and as worthwhile human beings in-and-of themselves. Accordingly, you must always focus on the company's or organization's greatest resource - its people. Consequently, never forget that no one will long follow you as a leader, and you will never achieve long-lasting personal and organizational success, if you are not a law-abiding, ethical, moral, and socially and environmentally responsible person.

\section{Self-Interest}

The United States is a democratic, capitalistic republic. Accordingly, there is nothing wrong with self-interest and to ethically increase your personal wealth, and as a result becoming very successful and making a lot of money. As Adam Smith long ago said, you will benefit, and society will benefit too as there will be more and better goods, services, and efficiencies. So have a good and strong work ethic; and do not be wary of a "little hard work." There is no substitute for hard work and persistence, the authors emphasize, which will pay off in long run. In addition, save money (and for a young person starting out we suggest at least $10 \%$ of monthly earnings). Also, you should prepare a budget; keep track of expenses; know the difference between wants and needs; and, as emphasized, save money for yourself and for your business, especially when the "times are good" in case, as is likely in life, the "times are bad"

\section{Stress}

Stress is inevitable in life, particularly in business, and especially at the leadership level; but list your "stresses" and "stressors." Then take small but concrete and effective steps to reduce and eliminate them. It will be most helpful to have a "family life," which will bring balance to your life. Accordingly, achieve "work-life" balance; and as such allow yourself time to relax, reenergize, and reset. In addition, understand that employees have stress too as well as a life outside of work.

\section{Professionalism}

Strive to be a professional in every action you take, that is, engage in appropriate conduct and dress code. Remember that you will be representing a company or organization and its brand and image. Also, note that ultimately you will want to be a leader who needs followers who will want to follow and work for a leader that exhibits a professional demeanor. So be mindful of your actions, obviously including personal habits, and especially, your social media usage. Be responsible, reliable, and dependable (and at a high-level). Develop a reputation for integrity, ethics, honesty, and trust; demonstrate respect for people; and be fair-minded and impartial in your dealings with people. Moreover, you must exhibit social and environmental responsibility (that is, sustainability). Accordingly, be a volunteer; help others; have company community, charity, and "give-back" events; and allow employees time off to volunteer. All the foregoing characteristics are all essential hallmarks of the "professional" person.

\section{Risk-Taking}

To be successful at some point it will be necessary to take some risks. So, take some calculated risks, but look for intelligent though risky propositions, whereby you have a good chance for success. Be willing to challenge beliefs and perceived "truths." Look for opportunities and be prepared to take advantage of those apparent opportunities. Yet also create opportunities where you can apply your knowledge and skills. Be entrepreneurial, innovative, nimble, and adaptable; have a strategy for success; and have a teamoriented culture that is exciting and inspires innovation, creativity, and success. Be a "shaper" and not a mere "reactor"; and thus be willing and able to respond to new favorable circumstances as well as to create new circumstances. As Niccolo Machiavelli said, "be bold," but also note that he said, "Fortune favors the young because they are bold."

\section{“Good Luck"}

Clearly, it is very good and most helpful to have "good luck," good fortune, and to be in the "right place at the right time." Yet, the authors submit that you can "make your own luck" by persistence and perseverance, educating and empowering yourself, being competitive, and taking advantage of apparent and upcoming opportunities. The old maxim is true, that is, "the harder you work the luckier you will get." Also true is the old maxim that "a talented person is a lucky person; and a lucky person is a talented person." Overcome bad luck, rejection, and disappointment, which are inevitable in life; certainly, do not take rejection personally. Be positive, work hard, set attainable goals and work persistently to achieve them, look for and create opportunities, and thereby create your own success. As noted, it helps to be young and thus to be bolder and more willing to take risks. In addition, it helps to be in a business environment that is the "land of opportunity," especially for entrepreneurs. 


\section{Leadership}

Leadership is about having a vision of the future and influencing others to take appropriate actions towards this direction and goal. Ultimately, you need to learn and develop your own leadership character, talents and skills to effectively influence others. If people believe you are honest, hardworking, bright, intelligent, and ethical, then they are more likely to believe your ideas and trust you. So, practice and develop your leadership skills. Strive to be the leader of a team, department, division, and eventually an organization. Develop innate leadership skills; and refine your leadership skills. As such, know and understand your leadership style. Always ask the following key questions: do you lead by example, how do you make decisions, how much input do you get and from whom, what do you delegate and to whom, what (hard) work do you do for yourself, what do you delegate to others, what motivation techniques do you use, do you empower or micro-manage your employees, and, most importantly, how do you respond to problems (for example, in a calm and confident demeanor, admitting mistakes and not shifting blame, assuring the problem will not happen again, getting feedback from team members and employees on how to avoid in the future, and trying to use unfortunate circumstances to create something positive)?

When you are at the appropriate leadership level, provide team members and employees with the relevant resources, education, training, and skills needed to be successful. You thus must become a teacher, mentor, and coach for others. You especially must recognize and empower ethical and competent people. Allow and encourage team members and employees to collaborate and share their ideas with you and other members of the organization. As a leader, have a vision and the values, drive, motivation, and be ability to "sell" that vision to others, and then to motivate key people to work with you and others to achieve that vision.

\section{Formulas for Success}

Based on the preceding discussions and suggestions, we offer to you the following practical "formulas" for success; that is, for you to gain that competitive advantage, for you to "win the game" of business or other endeavors, to obtain position and power, and to make money. The first formula is known as the "7 P's" Formula for Success," consisting of the following elements:
i. plan,
ii. performance,
iii. patience,
iv. persistence,
v. passion,
vi. politeness, and
vii. presence.

The next formula is the "Success Triad," consisting of the following elements:
I. "sound" decision-making,

II. adherence to core values, and

III. taking a long-term approach. Finally, the authors submit that one must adhere to the aforementioned formulas; and then one must ask, and answer satisfactorily, the following questions when contemplating an action or decision: Is it legal based on the law? Is it moral based on ethics? Moreover, what should a socially responsible and environmentally responsible company or organization be doing?

Accordingly, the authors submit that if you do all the foregoing points you and your business or organization will be successful, and you will be able to sustain that success, and as a result, you, your family, your business and organization and its stakeholders, including the local community and society as a whole, will benefit.

\section{Summary}

As authors, we fully and enthusiastically believe that if you comprehend the philosophical underpinnings of leadership and then follow the aforementioned practical recommendations (see a summary list in Appendix, gained from experts and researchers), there is a great future for you to be an effective leader and successful.

Success means being profitable, of course, but always remember the motto of the old city-state of Venice: "For the Profit and Honor of Venice." That is, be very successful but in an honorable manner, that is, adhering to the law and ethical and moral norms as well as being socially responsible. Therefore, we strongly recommend that you first focus on being an effective leader in the service of society and others through your unique knowledge and skills; and as a result, "success" will be the natural corollary of your hard work, diligence, and social responsibility. You will be a successful leader on a sustainable basis. Finally, as authors and educators, we truly tell you that one of our greatest satisfactions is your success.

\section{Appendix}

\section{Leadership Success Practices}

The following list is a summary of the specific reminders, suggestions, tactics, and strategies for effective leadership and personal and organizational success presented and examined in the article (Eckfeldt[16]; Gilbert[17]; Schwantes[18,19]; Tullman[20] 2019; Noe, Hollenbeck, Gerhart and Wright[21]; ChengTozun[22]; Cohan[23]; DesMarais[24]; Economy [25]; Haden[26]; Thomas[27]2017; Amdur [28]; Boitnott [29]; Cavico and Mujtaba, 2014):

1. Set worthy AND attainable goals.

2. Aim high; think "big" but start out modestly; break down your goals into smaller and more manageable and thus more achievable objectives.

3. Fit your short-term objectives into your long-term goals.

4. Be committed to attaining your goals; be passionate; yet be patient but persistent. 
5. Gain new skills, knowledge, expertise, training, education and professional development; be prepared to "re-tool" yourself if necessary; develop "hard skills".

6. Develop "soft-skills," that is, positive attitude, good work ethic, honesty and integrity, good communication, culture-fit, and critical thinking.

7. Develop strong collaboration skills; be able to collaborate to achieve organizational strategies and goals.

8. Challenge non-proven beliefs and perceived "truths".

9. Make sure you have basic competencies in the "3-Rs": reading, writing, and arithmetic.

10. Accelerate, expand, and improve your scope and rate of learning.

11. Use common sense, even when the numbers might show otherwise.

12. Find out what you like to do and do it well. Note that you do not have to be good in everything; realize that others will be able to assist you in weak areas.

13. Find out what you do not like to do and do not do well; do not worry if you are not sure what direction to take - you will figure it out.

14. Find what you love to do. Remember that old maxim: "There is a person for every job, and a job for every person". You can start part-time, temporary, and or entry-level, and then acquire the needed knowledge, skills, and experience, and thus advance to full-time.

15. Learn by doing and learn from mistakes; admit mistakes; be willing and able to be educated and trained; "own" your errors and be able to move forward from them; take responsibility for your actions (which is what trustworthy people and leaders do).

16. Look for professional and respected role models; learn from successful people; seek their counsel.

17. Learn from mentors and coaches; look for a leader who nurtures talent and those that are willing to spend time with you, take an interest in you, and answer the questions you ask; look for a leader who is willing to "take a chance on you".

18. Achieve excellence; become recognized as being very good at something; be regarded as a "go-to" person; help to take work away from boss and to reduce the stress and workload of the boss; be recognized as a high-achiever.

19. Strive to be the leader of a team, department, division, and organization; provide people with education and training/ skills needed to be successful; be a teacher of others.

20. Engage, delegate and empower competent people; allow team members to collaborate and share their ideas.
21. Develop innate leadership skills; also learn and refine leadership skills; know and understand your leadership style.

22. View employees as "human investments"; as employees grow and develop so too will you and your organization, including its profitability.

23. Create an environment where employees feel they can voice their opinions freely without fear of repercussions.

24. Develop relationships at work - mentors/coaches, confidantes, friends.

25. Look for hidden and untapped potential in employees and others and seek to draw them out into jobs or tasks you feel they would do well.

26. Create and develop collaborative relationships where both parties receive value.

27. Be positive, passionate, excited; you will attract likeminded people.

28. Celebrate achievements and recognize accomplishments, which will create high morale, motivate employees, and thus increase productivity.

29. Create a culture of respect, mutual support, caring, openness, and success; and a culture of happiness and fun too.

30. Create a culture of respect, recognition, and well-earned and well-deserved rewards.

31. Help employees achieve their goals - both inside and outside the company; ensure that employees have the tools they need to get the job done.

32. Guide employees, give direction, but also empower them and serve as a role model.

33. Express gratitude, by saying "thank you" for work well done and/or help and assistance.

34. Value diversity among people and be cognizant of the fresh ideas, opinions, and perspectives they can bring forth.

35. Talk to employees; and try to link or align company's vision and values with those of associates.

36. Create opportunities for advancement and growth.

37. Stress is inevitable, but list your "stresses," and encourage the employees to do so, and then take small but concrete and effective steps to effectively manage, reduce and eliminate them.

38. Save money; prepare a budget; keep track of expenses; know difference between wants and needs.

39. Have a "family life," to achieve "work-life" balance; allow time to relax, reenergize, and reset.

40. Build relationships with people; get counsel "feedback" from others - family, co-workers, clients, customers; listen to 
different points of view.

41. Practice professionalism; remember that you will be representing your own brand or those of your organization.

42. Be responsible, reliable, and dependable (and at a highlevel).

43. Develop a reputation for integrity, ethics, honesty, trust; demonstrate respect for people; be fair-minded and impartial in your dealings with people.

44. Always treat people with respect and dignity; demonstrate that the company cares about its employees as individuals; always focus on the company's greatest resource - its people.

45. Encourage environmental responsibility (sustainability); be a volunteer; help others; and allow employees time off to volunteer.

46. Help others at work; help them "pick-up the slack"; invite co-workers to lunch; organize office activities; the result will be more engaged employees.

47. Remember that employees have a life outside of work.

48. Be optimistic and practice maintaining a positive attitude at all times.

49. Have a "pleasant personality," forgiving, compassionate; be patient with other people's mistakes

50. Be open and transparent with people.

51. Give praise when well deserved; the result will be to give employees the drive and motivation to do excellent work.

52. Be modest; be humble; avoid arrogance; be willing to share credit for successes.

53. Avoid negativity and negative people; associate with positive people; and do not be negative with yourself; do not admonish yourself.

54. Look for people who are happy and satisfied with life, and hire and promote them, as they usually will be very productive and not negative.

55. Do not use profanity and do not do drugs. No one is going to hire you if you use drugs or if you constantly use profanity in your daily language.

56. Take some calculated chances/risks, but intelligent ones; look for opportunities; take advantage of opportunities; create opportunities where you can apply your knowledge and skills.

57. Be entrepreneurial, innovative, nimble, and adaptable; have a strategy for success; have a team-oriented culture that is exciting and inspires innovation, creativity, and success.

58. Be a "shaper" and not a mere "reactor"; be willing and able to respond to new circumstances.
59. Be aware of "blind-spots" (areas that you need to develop) and "hidden-strengths," that is, talents/skills that you are not using and/or publicizing.

60. Take a long-term perspective; be willing to undergo some short-term sacrifice and expense to maximize your own greater long-term good.

61. Execute your strategy for success; have "to-do" lists; have strategic goals and objectives, achieve them, and then set more goals/objectives.

62. Prioritize: Have a clear, definite, and achievable set of priorities.

63. Learn to train, develop, trust, and empower others. Achieve a proper balance between the time and effort you need to manage the business or organization and the time you need to work yourself on critical projects.

64. When new issues or problems emerge, be careful not to overload or overwhelm yourself with work; rather, be prepared to re-order your priorities and thus to delegate work to others.

65. Be a "good" delegator; that is, do not merely "hand-off" projects to others, but choose your delegates carefully based on knowledge, skill, training, and motivation.

66. Be aware of globalization; be aware of the laws of the host countries you are doing business in while acting responsibility.

67. "Make your own luck" by persistence/perseverance, empowering yourself, being competitive, and taking advantage of opportunities; the harder you work the luckier you get.

68. Learn from rejections; do not take rejection personally; create your own success.

69. Practice the "7 P's" of success: plan, performance, patience, persistence, passion, politeness, and presence.

70. Gain a sustainable competitive advantage through "sound" decision-making, adherence to core values, and by taking a long-term and sustainable approach.

\section{Acknowledgement}

None.

\section{Conflict of Interest}

No conflict of interest

\section{References}

1. Mujtaba BG (2010) Workforce Diversity Management: Challenges, Competencies and Strategies. USA.

2. Cavico FJ, Mujtaba BG (2014) Business Ethics: The Moral Foundation for Effective Leadership, Management, and Entrepreneurship. Pearson Publications, England.

3. Mujtaba BG (2014) Managerial Skills and Practices for Global Leadership. USA.

4. Albrecht, Karl (2006) Social Intelligence: the New Science of Success. Jossey-Bass. USA. 
5. Mujtaba BG (2019) Leadership and Management Philosophy of Guzaara or Cooperating to Get Along in South Asia's Afghanistan. Business Ethics and Leadership 3(1): 44-57.

6. Curtin, Melanie (2019) Strategies for dealing with a horrible boss. Florida, pp. 6D.

7. Senathip T, Mujtaba BG, Cavico FJ (2017) Policy-Making Considerations for Ethical and Sustainable Economic Development. Economy 4(1): 7-14.

8. Cavico FJ, Mujtaba BG (2016) Developing a Legal, Ethical, and Socially Responsible Mindset for Sustainable Leadership. USA.

9. Ahmed AM, Yang JB, Dale BG (2003) Self-assessment methodology: The route to business excellence. The Quality Management Journal 10(1): 43-57.

10. Ahn MJ, Adamson JSA, Dornbusch D (2004) Leaders to leadership: Managing change. Journal of Leadership and Organizational Studies 10(4): 112-123.

11. Sungkhawan J, Mujtaba BG, Swaidan Z, Kaweevisultrakul T (2012) Intrapreneurial Workplaces and Job Satisfaction: The Case of Thai Employees. Journal of Applied Business Research 28(4): 527-542.

12. Allegretti JG (2000) Loving your job finding your passion: work and the spiritual life. Paulist Press, USA.

13. Wolf F, Mujtaba BG (2011) Sustainability in Service Operations. International Journal of Information Systems in the Service Sector 3(1): $1-20$.

14. Alon I, McAllaster C (2009) The Global Footprint of an MBA. Journal of Studies in International Education 13(4): 522-540.
15. Economy, Peter (2018) The employees speak. Florida, pp. 6D.

16. Eckfeldt, Bruce (2019) How leaders can avoid commitment issues. Florida, pp. 6D.

17. Gilbert, Mandy (2019) Boss Moves: 6 ways to be a better leader. Florida, pp. $5 \mathrm{D}$.

18. Schwantes, Marcel (2019) Conflict Revolution. Florida, pp. 5D.

19. Schwantes, Marcel (2017) Time to Get Productive. Florida, p. 1.

20. Tullman, Howard (2019) Game Over.Florida, pp. 6D.

21. Noe RA, Hollenbeck JR, Gerhart B, Wright PM (2019) Human Resource Management: Gaining a Competitive Advantage. USA.

22. Cheng Tozun, Dorcas (2018) It is all about gratitude. Florida, USA.

23. Cohan, Peter (2018) Happiness is good for business. Florida, pp. 5D.

24. DesMarais, Christina (2017) Executives tell how they make it work. Florida, p. 1.

25. Morin, Amy (2018) Workplace Bully Behavior. Florida, pp. 5D.

26. Haden, Jeff (2017) Path to promotion. Florida, pp. 5D.

27. Thomas, Andrew (2017) Straight talk about success. Florida, pp. 5D.

28. Amdur, Eli (2017) Excellence is not an act but a habit. Bergen Record, Norway.

29. Boitnott, John (2017) 7 beliefs that hamper success - and how to change them. Florida. 